\title{
Avoidance of Over Speed Through Intelligent Speed Breaking System
}

\author{
M S Satyanarayana*, Aruna T M, Divya G N \\ Department of Computer Science \& Engineering, Sri Venkateshwara College of Engineering, Bengaluru, India
}

\begin{tabular}{l} 
Article Info \\
\hline Article history: \\
Received Jan 13, 2018 \\
Revised Mar 1, 2018 \\
Accepted Mar 9, 2018 \\
\hline
\end{tabular}

\section{Keyword:}

Accidents

Driving awareness

Intelligent speed break

Locations

Traffic awareness

\begin{abstract}
Accidents have become major issue in Developing countries like India now a day. As per the Surveys $60 \%$ of the accidents are happening due to over speed. Though the government has taken so many initiatives like Traffic Awareness \& Driving Awareness Week etc.., but still the percentage of accidents are not getting reduced. In this paper a new technique has been introduced in order to reduce the percentage of accidents. The new technique is implemented using the concept of Intelligent Speed Braking System. The Intelligent Speed Braking systems can be implemented any where essential in order to avoid the accidents. The main objective of this system is to calculate the speed of the vehicle at three different locations based on the place where the vehicle speed has to be controlled and if the speed is greater than the designated speed in that road then it will automatically open up the speed breaker to control the speed of the vehicle. If the speed is less or equal to the designated speed in that road then the vehicle will be passed without any disturbance. This system though it won't avoid $100 \%$ accidents at least it will reduce the percentage of accidents. This is system is not only to avoid accidents it will also intelligently controls the speed of the vehicles and creates awareness amongst the drivers.
\end{abstract}

Copyright $(0) 2018$ Institute of Advanced Engineering and Science. All rights reserved.

\section{Corresponding Author:}

M S Satyanarayana,

Department of Computer Science \& Engineering,

Sri Venkateshwara College of Engineering,

Off International Airport Road, Vidyanagar, Bengaluru - 562 157, India.

Email: satyanarayanams@ outlook.com

\section{INTRODUCTION}

In Developing countries like India the only solution to avoid accidents or any incidents which are happening either knowingly or unknowingly is by providing smart solution to it. In this paper the solution which is discussed is very smart way of controlling the speed of the vehicles whenever or wherever it is essentials.

This system works in three step process. In first step the speed of the car is calculated at $200 \mathrm{M}$ before the Intelligent Speed Breaker kept. And same will be informed to driver through some mean of message.

If the driver still going with same speed or higher speed again the sped is calculated at $100 \mathrm{M}$ and 50 $\mathrm{M}$ to calculate the average speed.

If the average speed is greater than it supposed to be in that particular road then immediately the intelligent speed breaker will be opened in different intervals based on the average speed to control the speed of the vehicle in order to avoid accidents. 


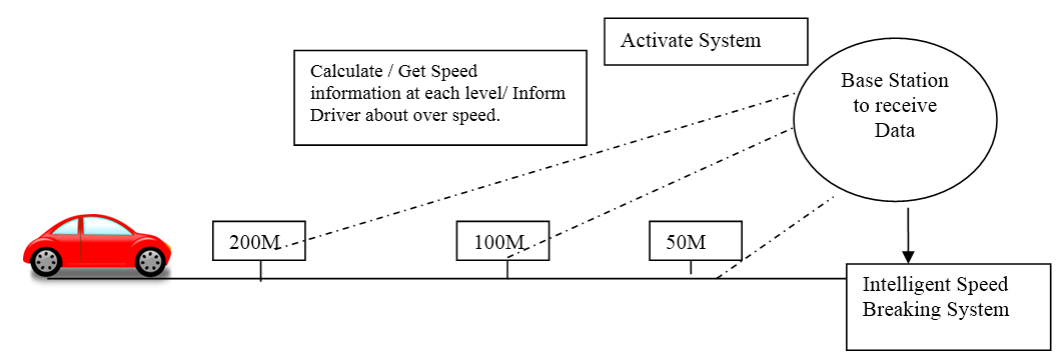

Figure 1. Architecture of Intelligent Speed Breaking System

\section{LITERATURE SURVEY}

Speed thrills but it also kills! Over Speeding made people to lose not only their life and also the people who are on the road and coming opposite side. As per the statistics available with the Traffic police of Bangalore, it shows that out of 1647 road accidents that took place last year, 456 accidents were caused due to over Speeding. It shows more than $25 \%$ accidents are due to over speeding.

So by considering this scenario the intelligent traffic system idea has been evolved to control at least $10 \%$ accidents out of $25 \%$ which happened last year not to repeat this time.

\section{ALGORITHM OF INTELLIGENT SPEED BREAKING SYSTEM}

a. Start

b. Calculate the speed of the vehicle before 200M from the Speed Braking System.

c. Send Message to Driver Regarding Over Speed.

d. If the Driver is going at minimal speed send him a message informing to follow same till reaches destination.

e. Else inform speed to Driver and also the maximum speed in that road through any of the communication media.

f. Again calculate the speed of the vehicle at $100 \mathrm{M}$ to check whether he is following the rules or not.

g. If yes then let him pass through the speed breaking system without any disturbance.

$\mathrm{h}$. If he is going in over speed inform him he needs to reduce the speed otherwise check once again speed at the 50M.

i. Calculate the average speed of $100 \mathrm{M}$ and $50 \mathrm{M}$ if it crosses more than what it supposed to be in that road then send signal to base station to operate intelligent speed breaking system.

j. The Intelligent Speed breaking system will be operated based on the average speed of the vehicle in order to control the speed of the vehicle.

k. Stop.

\section{PROTOTYPE}

This prototype is tested in three different scenarios to find the results.

Scenario 1: In the first scenario tested vehicle going in the determined speed that means actual speed supposed to be, there is no problem and the speed breaker is not opened.

Scenario 2: In the Second Scenario, the vehicle started slowly and when it reached 100M it is having speed greater than it supposed to be and message has been given to vehicle. Later the vehicle speed has been verified at 50M distance and passed the vehicle smoothly.

Scenario 3: in the third scenario the vehicle is coming very fast at $200 \mathrm{M}$ and the message has been given to deriver still the driver is going at the same speed at $100 \mathrm{M}$ then immediately one more message has been given to driver and verified speed at 50M but still the speed is same Immediately message has been sent to Speed Breaker to activate and the car driver reduces speed of the car after seeing the speed breaker.

The entire system is working fine the only disturbance observed is at finding the vehicle speed as it has so many limitations.[1-7] 


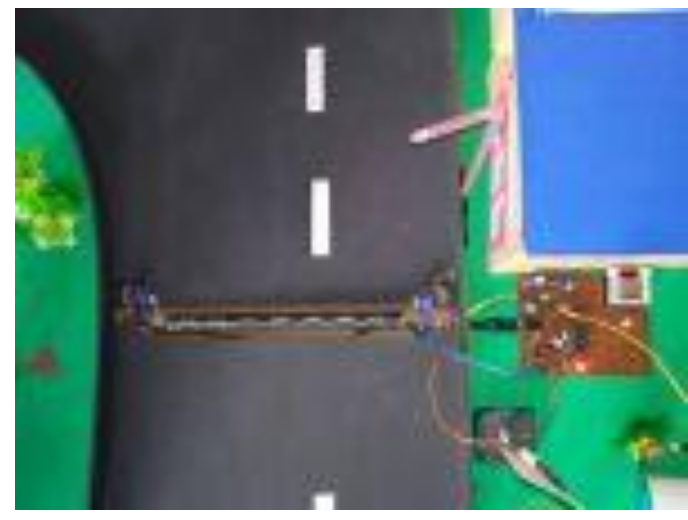

Figure 2. Prototype of the System

\section{CONCLUSION}

This system may not reduce $100 \%$ accidents which are happening due to over speed. At least we can reduce 30 to $40 \%$ accidents which are happening due to high speed to save the lives of the people.

\section{FUTURE ENHANCEMENT}

In future the system might be improved such a way that a device can be fitted to each and every vehicle at the time of manufacturing which intern will work as multipurpose device where the message will be sent to that particular device both as a Display device and also it gives voice instruction to the driver. And driver can also listen FM, Songs from the same device.

\section{REFERENCES}

[1] M. S. Satyanarayana, Murali Mohan B M, Raghavendra S N. "Intelligent Traffic System to Reduce Waiting Time at Traffic Signals for Vehicle Owners", Springer AISC Series, Chapter 31, Volume 668.

[2] Satyanarayana M.S. "Reducing the Waiting Time at Toll Gates Using National E- Tolling System "International Research Journal of Advanced Engineering and Science ISSN: 2455-9024. 1(2): 100-102.

[3] Rajeshwari Sundar, Santhoshs Hebbar, Varaprasad Golla. "Implementing Intelligent Traffic Control System for Congestion Control, Ambulance Clearance, and Stolen Vehicle Detection" IEEE Sensors Journal, 2015; 15(2) February.

[4] P. Lakshmi Pallavi, Dr. Mohammed Ali Hussain. "Intelligent Traffic Control System using Embedded Web Technology" IRACST - International Journal of Computer Science and Information Technology and Security (IJCSITS), ISSN: 2249-9555, 2014; 4(2), April.

[5] Khalil M. Yousef, Jamal N. Al-Karaki1, Ali M. Shatnawi. "Intelligent Traffic Light Flow Control System Using Wireless Sensors Networks" Journal of Information Science and Engineering, 2010; 26: 753-768.

[6] "Intelligent Traffic Control System" http://en.wikipedia.org/wiki/Intelligent Traffic Control System.

[7] https://plus.google.com/+ITCS/videos. 